\title{
FOAM SCLEROTHERAPY VERSUS MICRO STAB PHLEBECTOMY IN THE TREATMENT OF RECURRENT LEG VARICOSE VEINS
}

\author{
By
Yousef Abd El-Kareem Mohammed Younus, Ahmed Said Ahmed Daha and Hisham Wefky Anwar Hassan \\ Department of Vascular Surgery, Faculty of Medicine, Al-Azhar University, Cairo, Egypt \\ Corresponding author: Yousef Abd El-Kareem Mohammed Younus,
}

Phone: (+20)01151544404, (+20)01018675985, E-mail: joeyonis2017@ gmail.com

\begin{abstract}
Background: Varicose veins are common in the adult population and about one in four develops the condition throughout life.

Objective: To compare micro stab phlebectomy and foam sclerotherapy in the treatment of recurrent leg varicose veins regarding results of treatment, incidence of complications, and recurrence.

Patients and methods: This was a prospective observational cohort study included fifty patients with recurrent varicose veins divided in two equal comparative groups: Group A underwent stab phlebectomy and group B underwent foam sclerotherapy. The study duration was between January 2020 and November 2020 at the Department of Vascular Surgery, Al-Azhar University Hospitals (Al-Hussein and Bab Al-Shaareia University Hospitals).
\end{abstract}

Results: Thirty males and twenty females were included. Mean age (years) was 35 and 34 in phlebectomy and foam sclerotherapy groups, respectively. No significant difference between the two groups according to age and sex. The prevalence of recurrent lower limb varicose vein was found to be more common in males than in females in the vicinity of this study.

Dilated veins were the most common involving in $60 \%(\mathrm{n}=30 / 50)$ of the patients. The primary symptom of the patients relieved in $80 \%$ and $56 \%$ in phlebectomy and foam sclerotherapy groups, respectively. Time taken in procedures was significantly different between the two groups.

During the follow-up with duplex at 6 months, treated veins showed $92 \%(\mathrm{n}=23 / 25)$ removal of treated veins in the phlebectomy group, while only $72 \%(n=18 / 25)$ of the patients in the foam group showed evidence of complete occlusion. Recurrent varicose veins were found in $4 \%(n=1 / 25)$ of the patients in the phlebectomy group, while $16 \%(\mathrm{n}=4 / 25)$ of the patients in the foam sclerotherapy group had recurrence.

Conclusion: Both micro stab phlebectomy and foam sclerotherapy were safe effective in treating recurrent varicose veins with advantage of micro stab phlebectomy regarding to lower recurrence, primary symptom relief and better post procedural outcomes.

Keywords: Sclerotherapy, phlebectomy, recurrent varicose veins.

\section{INTRODUCTION}

Sclerotherapy is the injection of drugs capable of transforming the wall of a varicose vein into a fibrotic cord.
Permanent occlusion of veins should be the typical end point of sclerotherapy, but this does not always occur with liquid sclerosants. The main factor for insufficient sclerotherapy is represented 
by the volume of blood in which the drug will be diluted (McAree, 2015).

Micro stab phlebectomy (referred to as ambulatory phlebectomy, miniphlebectomy, hook phlebectomy, stab avulsion and Muller' phlebectomy) consists of removing varicose veins through 1-2-mm incision with a phlebectomy hook. Performing this in ambulatory setting requires local anesthetics. Social and economic advantages are accomplished due to the shortage of sedation, making it possible to perform varicose surgery in external ambulatory surgery centers. Obstacle of this method is peri-operative and postoperative pain, which is often not optimally controlled with standard local anesthetics (Krasznai et al., 2015).

Data on recurrence rates are hard to compare due to differences in the initial treatment, the way of measuring recurrence, and time of follow-up. The rate of recurrences increases with time (Chiesa et al., 2011). Neovascularization is the most common cause of recurrence and has been reported to account for $8 \%$ to $60 \%$ of recurrent varicose veins (Kostas et al., 2014).

Varicose vein surgery is characterized by a high recurrence rate of 20\%-60\% after 5 years and even higher after longer periods of follow up observation and recurrence may be due to several causes, e.g. neovascularization, inaccurate initial diagnosis, altered venous dynamics, progression of disease and inadequate initial surgery (Allaf and Welc., 2015).

The aim of the present study was to evaluate safety and efficacy of foam sclerotherapy and stab phlebectomy in treatment of recurrent varicose veins.

\section{PATIENTS AND METHODS}

Study design: A prospective observational cohort study. Study population: Fifty patients with recurrent lower limb varicose veins. Study duration: Between May 2020 and November 2020 at the Department of Vascular Surgery in Al-Azhar University Hospitals.

Inclusion criteria: Age between 20 to 50 years in asymptomatic and symptomatic recurrent lower limb varicose veins.

Exclusion criteria: Prior history of deep venous thrombosis, allergic to sclerosants, associated arterial disease or lymphedema, infectious dermatitis, cellulitis or severe peripheral edema, pregnant and lactating women, sapheno-femoral junction incompetence or sapheno-popliteal junction incompetence and KlippelTrenauny syndrome.

Pre-procedure Workup: Through history and clinical examination, the venous system was assessed. Revised Clinical-Etiology-Anatomy-

Pathophysiology (CEAP) documentation was done for all the patients and the disease severity was determined by Venous Clinical Severity Scoring (VCSS) (Sidawy and Perler, 2018). All eligible patients were comprehensively informed about the study and gave written informed consents. A duplex study of the venous system was done preoperatively. The site and the number of recurrent varicose veins was marked and noted. All target veins were traced and marked preoperatively both in supine and standing positions. They were randomly allocated using randomized block design, ensuring that subjects within each block are randomly assigned to undergo either micro stab 
phlebectomy (25 patients (15 males and 10 females)) or foam sclerotherapy (25 patients (15 males and 10 females)).

Micro stab phlebectomy: After tumescent anesthesia had been injected into the peri-venous tissues, a microincision was done near the vein. Longer vein segments were excised. Another incision was made at an equivalent distance, and the procedure was repeated. The puncture sites were covered with adhesive strips, sterile dressings, and wrapped with soft gauze rolls and stretch bandages.

Foam sclerotherapy was prepared by Tessari's technique and injected into superficial veins while the leg was elevated. Crepe bandage was finally applied. Duplex scanning was done at the sixth month of visit to assess the status of the treated veins.

\section{The parameters used were:}

a. Functional outcome return to normal activity/primary symptom relief.

b. Clinical outcome procedure time/change in disease severity assessed by venous clinical severity scoring and change in CEAP classification/course of venous ulcer.

c. Duplex outcome recurrence in treated veins/complete occlusion of treated veins.

\section{RESULTS}

This study included 50 patients with recurrent lower limb varicose vein 30 patients $(60 \%)$ are males and 20 patients $(40 \%)$ are females. Study shown insignificant difference between the two groups according to age and sex. Patients were categorized according to CEAP classification into two groups as the blow table. There was no significant difference between the two groups according to CEAP classification. In both males and females, the most affected age group was $31-40$ years with a mean age of 36 years. The prevalence of recurrent lower limb varicose vein was found to be more common in males than in females in the vicinity of this study (Table 1).

Table (1): Clinical and Demographic characteristics

\begin{tabular}{|l|c|c|}
\hline Parameters & Phlebectomy $(\mathbf{n = 2 5})$ & Foam Sclerotherapy $(\mathbf{n = 2 5})$ \\
\hline Mean Age (years) & $\mathbf{3 5}(\mathbf{1 8}-\mathbf{4 5})$ & $\mathbf{3 4}(\mathbf{2 3}-\mathbf{5 0})$ \\
\hline Females & $\mathbf{1 0}$ & $\mathbf{1 0}$ \\
Males & $\mathbf{1 5}$ & $\mathbf{1 5}$ \\
\hline CEAP C2-C3 (legs) & $\mathbf{2 2}$ & $\mathbf{2 0}$ \\
\hline CEAP C4-C6 (legs) & $\mathbf{3}$ & $\mathbf{5}$ \\
\hline
\end{tabular}


Among the presenting primary symptoms, dilated veins were the most common in $60 \%(\mathrm{n}=30 / 50)$ of the patients. Other presenting symptoms were distributed in this manner: Pain $(8 \% \mathrm{n}=$
$4 / 50)$, night cramps $(4 \% \mathrm{n}=2 / 50)$, edema (6 \% $\mathrm{n}=3 / 50)$, ulcer $(18 \% \mathrm{n}=9 / 50)$, itching $(2 \% \mathrm{n}=1 / 50)$, and bleeding ( $2 \%$ $\mathrm{n}=1 / 50$ ) Table 2)

Table (2): Presenting primary symptoms

\begin{tabular}{|c|c|c|}
\hline Symptoms & Number of patients & Percent \\
\hline Dilated veins & 30 & $60 \%$ \\
\hline Pain & 4 & $8 \%$ \\
\hline night cramps & 2 & $4 \%$ \\
\hline Edema & 3 & $6 \%$ \\
\hline Ulcer & 9 & $18 \%$ \\
\hline Itching & 1 & $2 \%$ \\
\hline Bleeding & 1 & $2 \%$ \\
\hline
\end{tabular}

The major clinical manifestation according to the revised CEAP classification were $\mathrm{C} 2$ (varicose veins; 46 $\% \mathrm{n}=23 / 50)$. The other manifestations included $\mathrm{C} 1$ (telangiectasia or reticular veins; $6 \% \mathrm{n}=3 / 50$ ), $\mathrm{C} 3$ (edema without skin changes; $12 \% n=6 / 50$ ), and $C 4$ (skin changes ascribed to venous disease; $10 \%$ $\mathrm{n}=5 / 50$ ), C5 (healed ulcers $14 \% \mathrm{n}=$ $7 / 50$ ), and C6 (active ulcers $12 \% \mathrm{n}=6 / 50$ ) Table 3)

Table (3): Major clinical manifestation according to the revised CEAP classification

\begin{tabular}{|c|c|c|}
\hline & Number of patients & Percent \\
\hline C 1 & 3 & $6 \%$ \\
\hline C 2 & 23 & $46 \%$ \\
\hline C 3 & 6 & $12 \%$ \\
\hline C4 & 5 & $10 \%$ \\
\hline C 5 & 7 & $14 \%$ \\
\hline C 6 & 6 & $12 \%$ \\
\hline
\end{tabular}

The primary symptom of the patient for which the patient was seeking medical attention relieved in $80 \%(n=20 / 25)$ of the patients in the phlebectomy group, whereas only $56 \%(\mathrm{n}=14 / 25)$ of the patients in foam sclerotherapy relieved from their presenting symptoms. The overall grading of relief at the end of the sixth months was $(+3)$ good improvement/ asymptomatic, (+2) moderate improvement, (+1) mild improvement, (0) unchanged, $(-1)$ mild worsening, $(-2)$ moderate worsening, (-3) marked worsening Table 2)

Table (4): Grading of primary symptom relief

\begin{tabular}{|c|c|c|c|}
\hline & $\begin{array}{ll}\text { Grading } & \text { Groups } \\
\end{array}$ & Phlebectomy & Foam sclerotherapy \\
\hline+3 & Good improvement/asymptomatic & $80 \%(n=20 / 25)$ & $56 \%(n=14 / 25)$ \\
\hline+2 & Moderate improvement & $12 \%(n=3 / 25)$ & $12 \%(n=3 / 25)$ \\
\hline+1 & Mild improvement & $8 \%(n=2 / 25)$ & $20 \%(n=5 / 25)$ \\
\hline $\mathbf{0}$ & Unchanged & Nil & $8 \%(n=2 / 25)$ \\
\hline-1 & Mild worsening & Nil & $4 \%(\mathrm{n}=1 / 25)$ \\
\hline-2 & Moderate worsening & Nil & Nil \\
\hline-3 & Marked worsening & Nil & Nil \\
\hline
\end{tabular}


The average procedure time was 40 min in micro-stab phlebectomy when compared to foam sclerotherapy which was $23 \mathrm{~min}$.

\section{Post-procedure symptoms:}

Pain was the most common symptom of the patients in both the groups (84\%; $\mathrm{n}=42 / 50)$. Other symptoms included transient skin pigmentation $(32 \% \mathrm{n}=8 / 25)$ and superficial thrombophlebitis $(20 \%$; $\mathrm{n}=$ 5/25) (Table 5).

Table (5): Post-procedure symptoms

\begin{tabular}{|l|c|c|}
\hline Symptoms & Number & percent \\
\hline Transient skin pigmentation & $\mathbf{8}$ & $\mathbf{3 2} \%$ \\
\hline Superficial thrombophlebitis & $\mathbf{5}$ & $\mathbf{2 0} \%$ \\
\hline Small ulcers & 2 & $\mathbf{8 \%}$ \\
\hline Transient loss of sensation & 1 & $\mathbf{4 \%}$ \\
\hline Bleeding & 1 & $\mathbf{4 \%}$ \\
\hline
\end{tabular}

Patients in both the groups resumed normal day-to-day activities after one day following the procedure, while $64 \%$ $(16 / 25)$ of the patients in the foam sclerotherapy group developed either itching, erythema or throbbing pain compelling them to use analgesics (mostly non-steroidal). During the follow-up with duplex at 6 months, treated veins showed $92 \%(n=23 / 25)$ removal of treated veins in the phlebectomy group, while only $72 \%$ $(n=18 / 25)$ of the patients in the foam group showed evidence of complete occlusion (Table 6).

\section{Table (6): Duplex examination}

\begin{tabular}{|c|c|c|}
\hline Guplex exam & Phlebectomy & Foam Sclerotherapy \\
\hline $\begin{array}{c}\text { Evidence of complete } \\
\text { occlusion }\end{array}$ & $23(92 \%)$ & $18(72 \%)$ \\
\hline
\end{tabular}

Recurrent varicose veins were found in $4 \%(\mathrm{n}=1 / 25)$ of the patients in the phlebectomy group, while in the foam sclerotherapy group were $16 \%(n=4 / 25)$ of the patients (Table 7).

Table (7): Recurrent varicose veins rate

\begin{tabular}{|c|c|c|}
\hline Groups & Phlebectomy & Foam Sclerotherapy \\
\hline $\begin{array}{c}\text { Recurrent } \\
\text { perforators }\end{array}$ & $1(4 \%)$ & $4(16 \%)$ \\
\hline
\end{tabular}

\section{DISCUSSION}

Varicose veins are common and affect about $40 \%$ of people in their lifetime. Its high incidence now contributes to a rise in healthcare expenditure. Conventional open surgery for varicose veins, involving a high ligation, stripping of the great saphenous vein (GSV) and multiple stab avulsions, was previously the gold standard treatment (Zhao et al., 2015).

Sclerotherapy is the chemical ablation of abnormal veins. The goal of therapy is 
irreversible fibrotic occlusion, followed by reabsorption of the target vessel (Venermo et al., 2016). Sclerosing agents damage the endothelial lining and subendothelial collagen fibers are exposed which initiates the coagulation cascade and results in thrombosis of the vessel. Although sclerotherapy was started as liquid sclerotherapy, this has gradually evolved into foam sclerotherapy. European consensus meeting on sclerotherapy has accomplished foam sclerotherapy superior over liquid sclerotherapy (Coleridge Smith, 2010).

Surgery improves lower limb symptoms, venous hemodynamics, and health-related quality of life (HRQL), so open surgery may be the standard in the treatment of the recurrent varicose veins, but it is associated with complications, morbidity, and delayed return to normal activities. So Thomasset concluded that FS represents an alternative offer to surgical treatment for varicose vein and confirmed that it is effective and safe (Thomasset et al., 2010).

The present study showed that clinical presentation of the patients showed the classic clinical presentation of the varicose veins. However, Pain, lower extremity edema, and visible varicosities were the most common presentations. Some of the patients were also bothered from the cosmetic appearance.

The results were supported by study of Gafar et al., (2019) as they reported that the clinical presentations of patients were disfigurement $(50 \%)$, pain $(60 \%)$, heaviness $(60 \%)$, and swelling $(70 \%)$ (Gafar et al., 2019). Mohamed et al., (2018) revealed that skin disfigurement represented $(45 \%)$, heaviness and pain representing (55\%) (Mohamed et al., 2018).

Patients who underwent stab phlebectomy had faster relief of symptoms than those who underwent foam sclerotherapy. In this study it was evident that venous ulcers healed faster with micro-stab phlebectomy than with foam sclerotherapy. Moreover, venous ulcers are more common in the male and have a significant impact on the quality of life.

In this study, we noticed that some varicose veins may be friable and hard to excise completely and this led to a suboptimal clinical outcome. Both stab phlebectomy and foam sclerotherapy not only revealed minimal time taken for return to normal activity but also proved to be safer regarding complications. However, the duration for performing foam sclerotherapy was shorter.

The present study showed one week follow up, duplex assessment revealed a radiologic success with complete obliteration of varicose veins in 16 patients $(64 \%), 16 \%$ underwent direct reinjection for further one or two injection sessions over the following two weeks until complete occlusion was obtained, $16 \%$ had thrombophlebitis (one of them had anterior tibial vein thrombosis), and $8 \%$ needed re-intervention but refused reinjection, $12 \%$ failed sclerotherapy and crossed over from that treatment to stab phlebectomy.

Foam sclerotherapy was a preferred method due to good contact of the drug with the vessel wall and less side effects. This benefit was more observed when closing larger veins. Depending upon the size of the vein, appropriate volume of 
foam should be matched. Excess volume of foam might result in migration of foam to deep veins causing deep vein thrombosis. Foam sclerotherapy is also known to have significant side effects such as visual disturbances, dry cough, neurological complications, thrombotic complications and other rare occurring side effects (Stücker et al., 2010).

In the study in our hands, one month follow up showed relieved of the primary symptom of the patient in $80 \%$ of the patients in the phlebectomy group, whereas in foam sclerotherapy only $56 \%$ of the patients were relieved from their presenting symptoms.

Furthermore, 6 months postoperatively, there was a higher percentage of occlusion of the treated veins in patients who were subjected to stab phlebectomy than those to foam sclerotherapy.

Though only 6 months of follow-up for all patients was insufficient, this duration was adequate to determine that the incidence of recurrence was less in patients who were treated by stab phlebectomy than by foam sclerotherapy. These results were supported by De Roos et al. (2013) as they found that the recurrence rate at 1 year following sclerotherapy was $25 \%$ compared to $2.1 \%$ in the phlebectomy group.

Nevertheless, surgeons treating recurrent varicose veins should accept the reality that recurrent/new varicose veins will develop in patients over time. This does not mean that treating recurrent varicose veins is a futile pursuit. Despite our best efforts, the present technique, technology, and knowledge cannot completely stop progression of all venous diseases. Long-term follow-up is needed to study the clinical outcome and late complications.

The use of duplex ultrasonography preand perioperatively during endothermal ablation, open surgery, and ultrasoundguided foam sclerotherapy (UGFS) is expected to reduce the incidence of tactical errors (Rasmussen et al., 2010).

\section{CONCLUSION}

Both micro stab phlebectomy and foam sclerotherapy were safe effective in treating recurrent varicose veins with advantage of micro stab phlebectomy regarding to lower recurrence, primary symptom relief, and better post procedural outcomes.

\section{REFERENCES}

1. Allaf N. and Welch M. (2015): Recurrent Varicose Veins: Inadequate Surgery Remains A Problem. Phlebology; 20:138-40.

2. Chiesa R, Marone EM, Limoni C, Volontè M. and Petrini O. (2017): Chronic Venous Disorders: Correlation between Visible Signs, Symptoms, and Presence of Functional Disease. J Vasc Surg., 46:322-30.

3. Coleridge Smith, P. (2010): Sclerotherapy and foam sclerotherapy for varicose veins. Phlebology, 24(6): 260-269.

4. De Roos KP, Nieman FHM. and Martino Neumann HA. (2013): Ambulatory Phlebectomy Versus Compression Sclerotherapy: Results Of A Randomized Controlled Trial. Dermatol Surg., 29(3):221-6.

5. Gafar, A. T., Omran, W. M., Alkhateep, Y. M. and Albatanony A. A. (2019): Evaluation of foam sclerotherapy in treatment of lower limbs-primary varicose veins. Menoufia Medical Journal., 32(4), 1234.

6. Kostas T, Ioannou CV, Touloupakis E, Daskalaki E, Giannoukas AD and Tsetis D. (2014): Recurrent Varicose Veins After Surgery: A New Appraisal Of A Common And Complex Problem In Vascular Surgery. Eur J Vasc Endovasc Surg., 27:275-82. 
7. Krasznai AG, Sigterman TA, Willems CE, Dekkers P, Snoeijs MG, Wittens CH, Sikkink CJ. and Bouwman LH. (2015): Prospective study of a single treatment strategy for local tumescent anesthesia in Muller phlebectomy. Ann Vasc Surg. A., 29(3):58693.

8. McAree, B. J. (2015): Optimisation of minimally invasive therapy for primary varicose veins (Doctoral dissertation, University of Leeds).

9. Mohamed, A. H., Soliman, A. H. and Abo El Maaty, M. E. G. (2018): Role of Ultrasound Guided foam Sclerotherapy in Treatment of Lower Limb Varicose Vein. The Egyptian Journal of Hospital Medicine., 72(5): 44244427.

10. Rasmussen LH, Bjoern L, Lawaetz M, Lawaetz B, Blemings, and Eklof B. (2010): Randomised Clinical Trial Comparing Endovenous Laser Ablation With Stripping Of The Great Saphenous Vein: Clinical Outcome And Recurrence After 2 Years. Eur J Vasc Endovasc Surg., 39:630-5.

11.Sidawy, A. N. and Perler, B. A. (2018): Rutherford's Vascular Surgery and Endovascular Therapy, E-Book. Elsevier Health Sciences, 23(155): 6659-6660.
12. Stücker, S. Kobus, Altmeyerp, and ReichSchupke, S, (2010): Review of published information on foam sclerotherapy. Dermatologic Surgery, 36(2): 983-992.

13. Thomasset SC, Butt Z, Liptrot S, Fairbrother BJ and Makhdoomi KR. (2010): Ultrasound Guided Foam Sclerotherapy: Factors Associated with Outcomes and Complications. Eur J Vasc Endovasc Surg., 40:389-392.

14. Venermo, M., Saarinen, J., Eskelinen, E., Vähäaho, S., Saarinen, E., Railo, M., and Vikatmaa, P. (2016): Randomized clinical trial comparing surgery, endovenous laser ablation and ultrasound-guided foam sclerotherapy for the treatment of great saphenous varicose veins. The British Journal of Surgery, 103(11): 1438-1441.

15. Zhao, Z-Y, Zhang, X-J. and Li, J-H. (2015): Comparison of high ligation and stripping of the great saphenous vein combined with foam sclerotherapy versus conventional surgery for the treatment of superficial venous varicosities of the lower extremity. Int J Clin Exp Med., 8: 7843-7848. 


\section{الحقن الرغوي مقارنة بالاستنصسال الوريدي بجرح طعني صغير في علاج دو الي الساق المرتجعة بالهان}

يوسف عبد الكريم محمد يونس, أحمد سعيد أحمد ضحا, هشام وفقي أنور حسن قسم جراحة الأوعية الدموية، كلية الطب, جامعة الأزهـر، القاهرة, مصر

E-mail: joeyonis2017@gmail.com

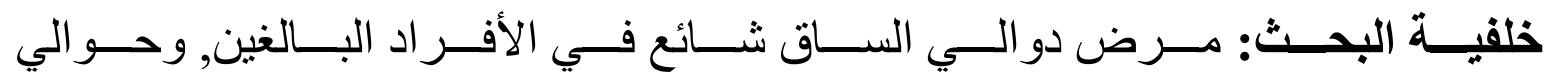
واحد من كل أربعة يصاب بهذا المرض طو ال الحياة.

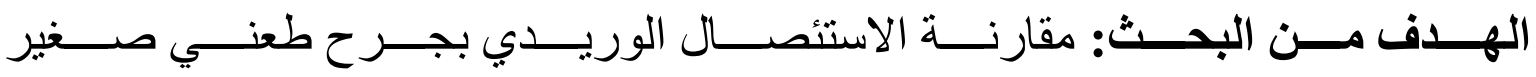

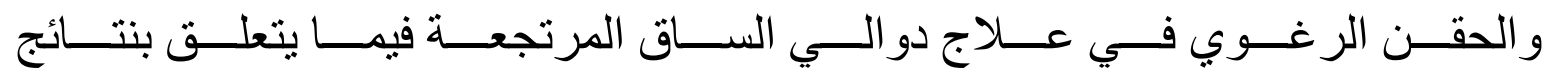
العلاج وحدوث المضاعفات ، وارتجاع الدو الي مرة أخرى.

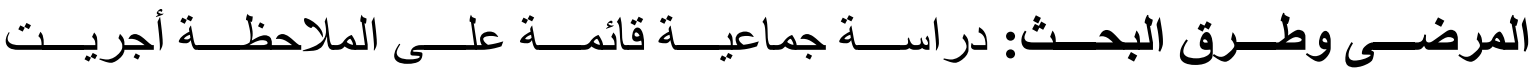

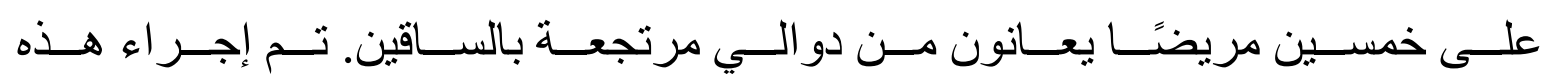

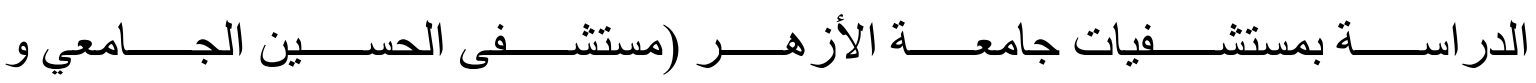

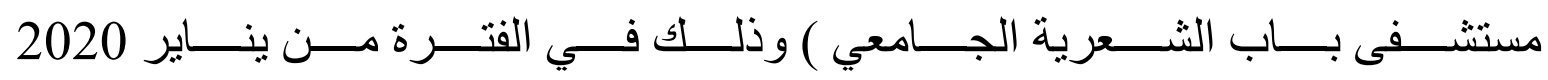

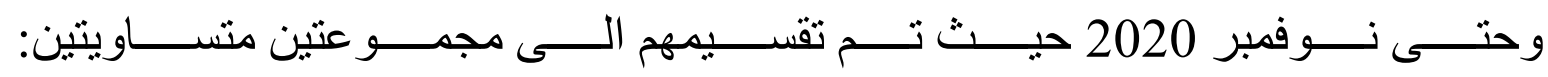

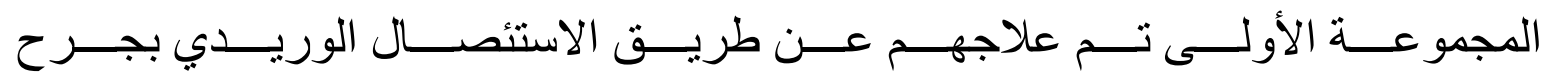
طعني صغير, والمجمو عة الثانية تم علاجهم عن طريق الحقن الرغوي.

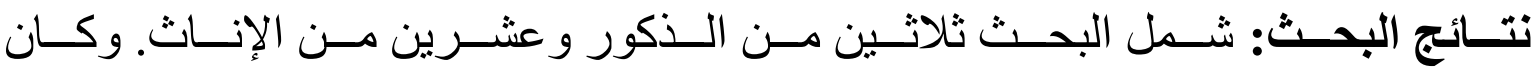

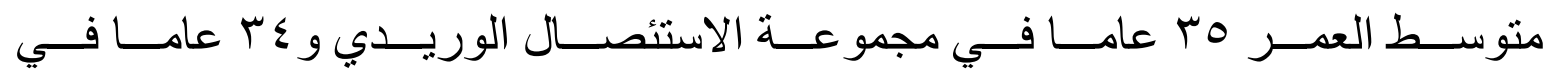

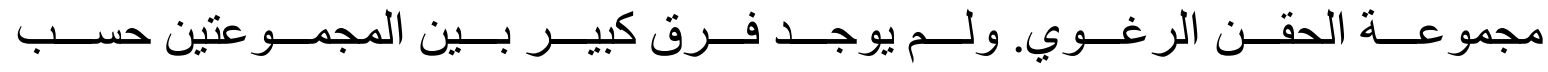

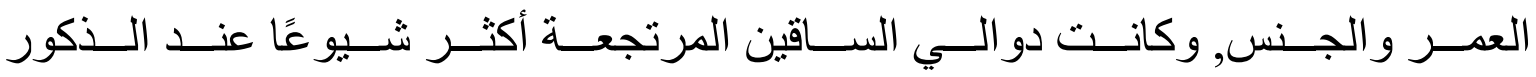

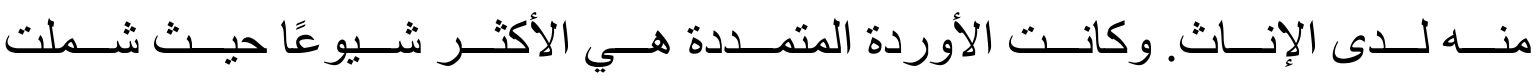

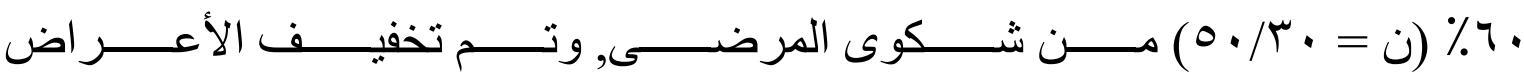




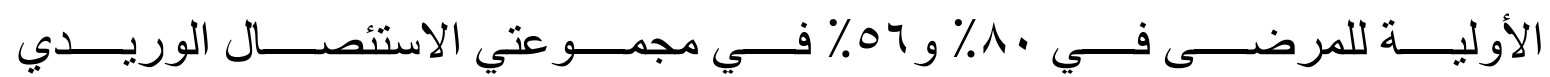

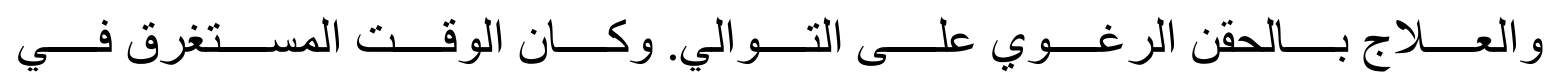

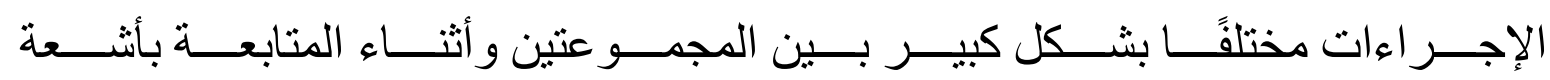

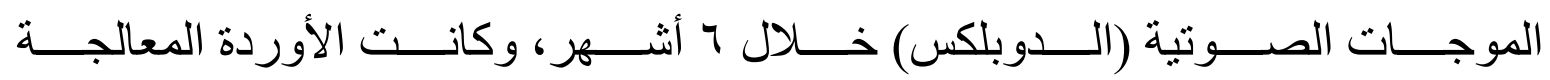

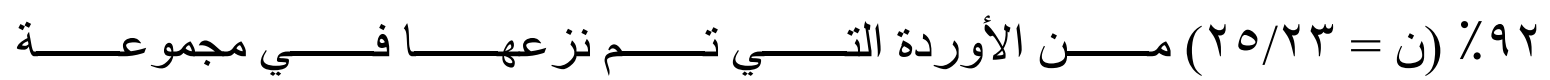

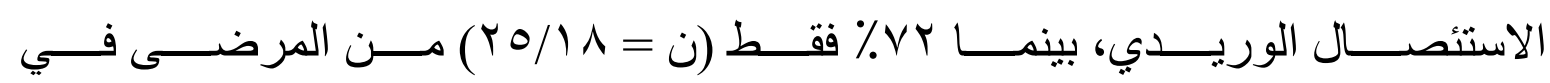

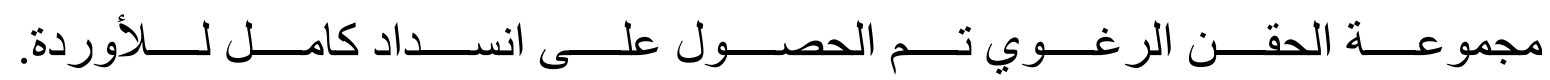

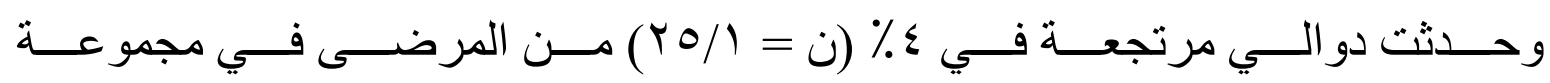

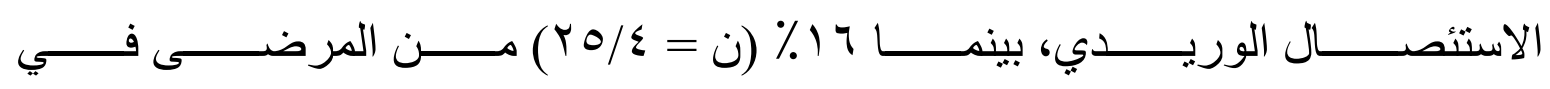
مجمو عة العلاج بالحقن الرغوي.

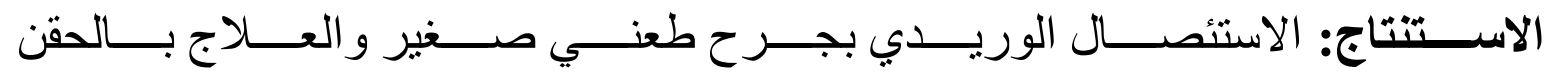

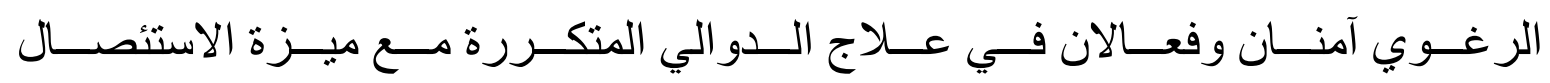

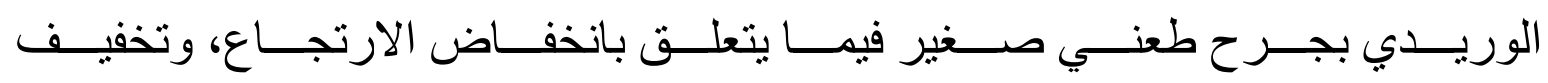
الأعر اض الأولية، ونتائج نهائية أفضل.

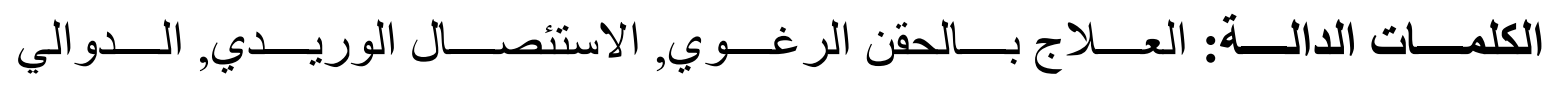
المرتجعة. 